\title{
Pengaruh Sikat Gigi Setiap Hari( 21hari) Dengan Pasta Gigi Yang Mengandung Fluor Menggunakantehnik Roll Terhadap Plakskor Di Sdn Keramat 3 Desa Sungai Tabuk Keramat
}

\author{
Siti Sab`atul Habibah' ${ }^{1}$, Danan² \\ 1,2 Poltekkes Kemenkes Banjarmasin Jurusan Keperawatan Gigi \\ email : sitibanjar67@yahoo.com
}

\begin{abstract}
Latar Belakang : Proporsi masyarakat yang menggosok gigi setiap hari sesudah makan pagi hanya $12,6 \%$ dan sebelum tidur malam hanya $28,7 \%$. Keadaan ini menunjukkan perlu ditingkatkan program sikat gigi bersama sesuai anjuran program di sekolah dengan mempertimbangkan sarana dan media informasi terutama pada usia dini, karena perilaku merupakan kebiasaan yang akan lebih terbentuk bila dilakukan pada usia dini, didukung dengan teori behaviour change melakukan sikat gigi setiap hari (21 hari) secara rutin, akan berdampak pada perubahan kebiasaan. Tujuan : Penelitian untuk mengetahui apakah ada Pengaruh Sikat Gigi Setiap Hari ( 21 hari) Dengan Pasta Gigi Yang Mengandung Fluor MenggunakanTehnik Roll Terhadap Plak Skor di SDN Keramat 3 Desa Sungai Tabuk Keramat. Metode : Jenis penelitian ini bersifat analitik dengan rancangan eksperimen semu (quasi experimental), sebagai akibat dari adanya perlakuan tertentu, rancangan penelitian pretest-postest. Populasi penelitian adalah murid SDN Keramat 3 Desa Sungai Tabuk Keramat dengan jumlah 105orang. Sampel penelitian Sampel penelitian diambil secara teknik Purposive Sampling dimana teknik pengambilan sampel didasarkan pada suatu pertimbangan tertentu yang dibuat sendiri berdasarkan cirri dan sifat-sifat populasi yang sudah diketahui sebelumnya. Sampel penilitian berjumlah 59 orang. Hasil : Penelitian Plak skor sebelum intervensi plak skor terendah 0.66, plak skor tertinggi 4.16, plak skor rata-rata 2.86. Plak skor sesudah intervensi plak skor terendah 0.00 , plak skor tertinggi 2.16, plak skor rata-rata 0.82 , nilai P. $0.000<$ dari Alfa 0.05 . Kesimpulan : ada pengaruh Sikat Gigi Setiap Hari ( 21 hari) Dengan Pasta Gigi Yang Mengandung Fluor menggunakan Tehnik Roll Terhadap Plak Skore di SDN Keramat 3 Desa Sungai Tabuk Keramat.
\end{abstract}

Kata kunci : sikat gigi, pasta gigi, tehnik roll

Copyright (C) 2019 Jurnal Skala Kesehatan. Politeknik Kesehatan Banjarmasin All rights reserved

Corresponding Author:

Siti Sab'atul Habibah

Poltekkes Kemenkes Banjarmasin Jurusan

Keperawatan Gigi Jln H. Mistar Cokrokusumo

Banjarbaru

Email : sitibanjar67@yahoo.com 
Background : The proportion of people who brush their teeth every day after breakfast is only $12.6 \%$ and before going to bed at night only $28.7 \%$. This situation indicates that a joint toothbrush program needs to be improved in accordance with the program recommendations in schools by considering means and information media, especially at an early age, because behavior is a habit that will be formed if done at an early age, supported by the theory of behavior change to brush teeth every day ( 21 days) regularly, will have an impact on changing habits. Objective : The study was to determine whether there was an effect of toothbrushes every day (21 days) with fluorine-containing toothpaste using a roll technique on score plaques in Keramat 3 Elementary School in Sungai Tabuk Keramat Village. MethodThis :type of research is analytical with quasiexperimental design (quasi experimental), as a result of certain treatments, the design of the pretest-posttest study. The study population was students of Keramat 3 Elementary School in Sungai Tabuk Keramat Village with 105 people. Research sample The research sample was taken by purposive samplingsampling technique wheretechniques are based on certain considerations made by themselves based on characteristics and characteristics of the population that have been previously known. The research sample amounted to 59 people. Results : The study plaque score before the plaque intervention score was the lowest 0.66 , the highest plaque score was 4.16, the plaque score averaged 2.86. The score plaque after plaque intervention was the lowest score of 0.00 , the highest plaque score was 2.16 , the plaque score averaged 0.82 , the value of P. 0.000 <from the 0.050 .05 . Conclusions : There is an effect of Toothbrushes Every Day (21 days) with Fluorine Toothpaste using the Roll Technique on Skore Plaques in Keramat 3 Elementary School in Sungai Tabuk Keramat Village.

Keywords : toothbrush, toothpaste, roll technique

\section{PENDAHULUAN}

Proporsi masyarakat yang menggosok gigi setiap hari sesudah makan pagi hanya $12,6 \%$ dan sebelum tidur malam hanya $28,7 \%$.Keadaan ini menunjukkan perlu ditingkatkan program sikat gigi bersama sesuai anjuran program di sekolah dengan mempertimbangkan sarana dan media informasi terutama pada usia dini, karena perilaku merupakan kebiasaan yang akan lebih terbentuk bila dilakukan pada usia dini, didukung dengan teori behaviour change melakukan sikat gigi setiap hari ( 21 hari) secara rutin, akan berdampak pada perubahan kebiasaan ${ }^{3}$

Hasil penelitian terbaru menunjukan bahwa 31\% responden tidak menggosok gigi setiap hari, 33\% responden tidak menggunakan sikat gigi sendiri, 10\% tidak menggunakan pasta gigi, 33\% menggosok gigi 1 kali dalam sehari. Hanya 3.7\% yang didapatkan menggosok gigi yang benar pagi setelah sarapan dan malam sebelum tidur, dan belum ada yang menggunakan metode menggosok gigi yang benar ${ }^{14}$

Keadaan fluor yang optimal dalam air minum (0,7 ppm) akanmemperkuat daya tahan email gigi terhadap karies. Peneli $\square$ an diKalimantan Barat, Kalimantan Selatan, Kalimantan Tengah, KalimantanTimur, Sulawesi Selatan, Maluku, dan Jambi menunjukkan bahwa kadar fluor dalam air minum di daerah tersebut 0,00 ppm, sehingga prevalensi karies di daerah tersebut cukup tinggiHeriandi dan Suwelo (1988) di Cipatat, Bandung menemukan kadar fluorida cukup tinggi $(0,75 \mathrm{ppm})$ dengan prevalensi karies yang rendah(56,46\%) dan DMF-T 1,34. Data air minum (air sumur, kali, sumber PAM,dsb) yang di kumpulkan Suwelo (1991) baik di pulau Jawa maupun di luar pulau Jawa menunjukkan kadar fluor yang rendah (kurang dari 0,3 ppm),3,14 
Tehnik roll merupakan cara yang paling sering dianjurkan karena sederhana tetapi efisien dan dapat digunakan diseluruh bagian mulut. Bulu-bulu sikat ditempatkan pada gusi sejauh mungkin dari permukaan oklusal dengan ujung-ujung bulu sikat mengarah ke apeks dan sisi bulu sikat digerakan perlahan-lahan melalui permukaan gigi, tehnik roll memiliki keuntungan menstimulasi gingival yang baik ${ }^{17}$

Plak memegang peranan penting dalam etiologi dua macam penyakit utama pada gigi dan jaringan pendukungnya, yaitu karies dan gingivitis. Oleh karena itu, salah satu diantara tindakan paling penting yang harus dilakukan oleh dokter gigi dan tenaga-tenaga pembantunya adalah usaha untuk mencegah atau setidaknya mengurangi pembentukan plak dengan tujuan mencegah penyakit penyakit tersebut ${ }^{8}$

Kondisi gigi yang kurang bersih maupun gigi yang berlubang merupakan tempat yang dapat menjadi media pertumbuhan bakteri anaerob gram negatif, disamping sisa makanan itu juga mengalami pembusukan ${ }^{8}$

Berdasarkan hasil wawancara dengan penduduk desa Sungai Tabuk Keramat, ada beberapa masyarakat Desa yang menggunakan air sungai untuk keperluan seharihari seperti memasak, minum mencuci dan sebagainya.Terutama di Desa sungai Tabuk Keramat, masih menggunakan air sungai untuk keperluan sehari-hari.

Data yang ditemukan pada saat studi pendahuluan, keadaan kebersihan gigi dan mulut yang diperiksa sebanyak 10 orang murid, 3 orang murid dalam kondisi buruk dan 7 orang dalam kondisi sedang, dengan rata-rata karies 4 gigi.

Tujuan Penelitian Untuk mengetahui apakah ada Pengaruh Sikat Gigi Setiap Hari ( 21 hari) Dengan Pasta Gigi Yang Mengandung Fluor Menggunakan Tehnik Roll Terhadap Plak Skor di SDN Keramat 3 Desa Sungai Tabuk Keramat

Hasil penelitian ini diharapkan dapat menjadi masukan dalam rangka meningkatkan upaya-upaya pencegahan karies dan menumbuhkan kebiasaan untuk memelihara kebersihan gigi dan mulut dengan menggosok gigi yang baik dan benar secara teratur, serta menggunakan pasta gigi yang mengandung flour memakai tehnik roll, sehingga derajat kesehatan gigi dan mulut dapat meningkat.Terutama pada di SDN Keramat 3 Desa Sungai Tabuk Keramat

\section{BAHAN DAN METODE}

Jenis penelitian ini bersifat analitik dengan rancangan eksperimen semu (quasi experimental), sebagai akibat dari adanya perlakuan tertentu ${ }^{7}$

Bentuk penelitian ini berupa rancangan " pretest - postest" digambarkan sebagai berikut

\begin{tabular}{llc} 
Pretest & Perlakuan & Postest \\
\hline 01 & $\mathrm{X}(\mathrm{a})$ & 02 \\
\hline
\end{tabular}

(Notoadmodjo,S.,2002).

Gambar 3.1 Rancangan Penelitian

Populasi penelitian adalah murid SDN Keramat 3 Desa Sungai Tabuk Keramat dengan jumlah 105 orang. Sampel penelitian diambil secara teknik Purposive Sampling dimana teknik pengambilan sampel didasarkan pada suatu pertimbangan tertentu yang dibuat sendiri berdasarkan ciri dan sifat-sifat populasi yang sudah diketahui sebelumnya. Sampel penilitian berjumlah 59 orang .

Cara Penelitian, responden diberi penyuluhan cara menyikat gigi tehnik roll dengan demontrasi, Periksa plak skor sebelum melakukan sikat gigi menggunakan pasta gigi yang 
mengandung fluor dengan tehnik roll, Melakukan sikat gigi menggunakan pasta gigi yang mengandung fluor dengan tehnik roll yang mana setiap gerakan diulang 8 kali , waktu dari menyikat gigi sampai kumur-kumur selama 2 menit, agar flour bisa meresap, Menyikat gigi setiap hari sebelum masuk kelas selama 21 hari, diawasi oleh peneliti dan guru yang sudah dilatih, Menyikat gigi pada malam hari sebelum tidur yang diawasi orang tua murid, Periksa plak skor sesudah melakukan sikat gigi menggunakan pasta gigi yang mengandung fluor dengan tehnik roll dihari ke 22.

\section{HASIL DAN PEMBAHASAN}

Pada tahapan ini pelaksanaan penelitian baru $75 \%$, dimana setelah empat belas kali sikat gigi plak skor terlihat ada perbaiakan. Pelaksananaa penelitian untuk pemeriksaan akhir sebanyak 21 kali

Tabel 4.1. Plak Skor Responden Sebelum intervensi

\begin{tabular}{l|c|c|c|c}
\hline Kegiatan & $\begin{array}{c}\text { Jumlah } \\
\text { Sampel }\end{array}$ & $\begin{array}{l}\text { Skor } \\
\text { Terendah }\end{array}$ & $\begin{array}{l}\text { Skor } \\
\text { Tertinggi }\end{array}$ & Rata-Rata \\
\hline $\begin{array}{l}\text { Sebelum } \\
\text { Intervensi }\end{array}$ & 59 & 0.66 & 4.16 & 2.86 \\
\hline
\end{tabular}

tabel 4.1, jumlah sampel sebanyak 59 orang dilihat hasil plak skor sebelum intervensi plak skor terendah 0.66, plak skor tertinggi 4.16, plak skor rata-rata 2.86.

Tabel 4.2. Plak Skor Responden Sesudah intervensi

\begin{tabular}{l|c|c|c|c}
\hline Kegiatan & $\begin{array}{c}\text { Jumlah } \\
\text { Sampel }\end{array}$ & $\begin{array}{l}\text { Skor } \\
\text { Terendah }\end{array}$ & $\begin{array}{l}\text { Skor } \\
\text { Tertinggi }\end{array}$ & Rata-Rata \\
\hline $\begin{array}{l}\text { Sebelum } \\
\text { Intervensi }\end{array}$ & 59 & 0.00 & 2.16 & 0.82 \\
\hline
\end{tabular}

tabel 4.2, jumlah sampel sebanyak 59 orang dilihat hasil plak skor sesudah intervensi plak skor terendah 0.00 , plak skor tertinggi 2.16 , plak skor rata-rata 0.82

Tabel 4.3 Hasil uji Paired Sampels Test

Paired Samples Test

\begin{tabular}{|c|c|c|c|c|c|c|c|c|c|}
\hline & & \multicolumn{5}{|c|}{ Paired Differences } & \multirow[b]{3}{*}{$\mathrm{T}$} & \multirow[b]{3}{*}{$d f$} & \multirow{3}{*}{$\begin{array}{l}\text { Sig. } \\
(2- \\
\text { tailed })\end{array}$} \\
\hline & & \multirow[b]{2}{*}{ Mean } & \multirow{2}{*}{$\begin{array}{c}\text { Std. } \\
\text { Deviatio } \\
n\end{array}$} & \multirow{2}{*}{$\begin{array}{c}\text { Std. Error } \\
\text { Mean }\end{array}$} & \multicolumn{2}{|c|}{$\begin{array}{c}95 \% \\
\text { Confidence } \\
\text { Interval of the } \\
\text { Difference } \\
\end{array}$} & & & \\
\hline & & & & & Lower & Upper & & & \\
\hline $\begin{array}{l}\text { Pair } \\
1\end{array}$ & $\begin{array}{l}\text { PLakskorseb } \\
\text { elum keg } \\
\text { sikatgigi - } \\
\text { Plakskorsesu } \\
\text { dah keg } \\
\text { sikatgigi }\end{array}$ & 2.04898 & .76280 & .09931 & $\begin{array}{r}1.850 \\
20\end{array}$ & 2.24777 & $\begin{array}{r}20.63 \\
3\end{array}$ & 58 & .000 \\
\hline
\end{tabular}


table 4.3 nilai P. 0.000 < dari Alfa 0.05, menunjukkan ada pengaruh Sikat Gigi Setiap Hari ( 21 hari) Dengan Pasta Gigi Yang Mengandung Fluor menggunakan Tehnik Roll Terhadap Plak Skore di SDN Keramat 3 Desa Sungai Tabuk Keramat

\section{PEMBAHASAN}

Penelitian yang dilaksanakan di SDN Keramat 3 Desa Sungai Tabuk Keramat, disambut positif oleh pihak sekolah, terbukti adanya kerjasama yang baik antara guru, murid, dan peneliti, sehingga penelitian dapat berjalan dengan lancer sesuai rencana.

tabel 4.1, jumlah sampel sebanyak 59 orang dilihat hasil plak skor sebelum intervensi plak skor terendah 0.66, plak skor tertinggi 4.16, plak skor rata-rata 2.86. ini menunjukkan kurangnya kesadaran pada anak dalam hal pemeliharaan kebersihan gigi dan mulut. orang tua juga mengalami kesulitan mengajarkan anak kebiasaan sikat gigi kepada anak-anaknya, sehingga kebersihan mulut anak masih banyak yang buruk. ${ }^{3}$

tabel 4.2 jumlah sampel sebanyak 59 orang dilihat hasil plak skor sesudah intervensi plak skor terendah 0.00 , plak skor tertinggi 2.16, plak skor rata-rata 0.82 . hasil ini menunjukkan perubahan kearah yang lebih baik, setelah melakukan sikat gigi selama 21 hari. Sesuai dengan Teori" behavior Change" mengatakan untuk mengubah kebiasaan seseorang maka diperlukan satu periode yang konstan dikondisikan kepada orang tersebut agar mengubah kebiasaanya. Dra. Sari Hermawan, psikolog, menjelaskan" Dalam 21 hari itu sendiri terbagi tiga tahap untuk membentuk memori yang memerintah pikiran dan tubuhnya melakukan kebiasaan baru yaitu : 7 hari pertama adalah perkenalan/introduction, dalam tahapan ajakan anakuntuk mengenal bentuk kegiatan dengan cara yang menyenangkan: 7 hari kedua adalah pengulangan/exercise, masuk dalam tahap latihan. Semakin sering anak melakukan gerakan tersebut, semakin anak lebih mudah hapal dan menikmati: dan terakhir 7 hari ketigalebih kearah penguatan/ Stabilization, dimana menuju pemantapan. Diharapkan "perilakupun terbentuk secara permanen menjadi suatu kebiasaan". Mari tanamkan sikat gigi secara teratur setiap pagi setelah sarapan dan malam hari sebelum tidur. ${ }^{14,17}$

Penurunan skor plak yang signifikan pada penelitian ini, selain membentuk suatu kebiasaan, juga didukung tehnik sikat gigi dengan tehnik roll merupakan gerakan sederhana, paling dianjurkan, efesien, menjangkau semua bagian mulut, ulangi gerakan ini sampai 8 kali sehingga tidak ada yang terlewat. Cara ini dapat menghasilkan pemijatan gusi dan membersihkan sisa makanan di daerah interproksimal ${ }^{8 .}{ }^{17}$, Menggunakan pasta gigi yang mengandung fluor juga sangat dianjurkan agar gigi menjadi kuat dan tahan terhadap karies karena mineral yang terkandung pada fluor bisa mengembalikan mineral yang hilang akibat adanya asam yang terjadi akibat proses metabolisme bakteri yang ada pada plak gigi $8,11,18$

\section{KESIMPULAN DAN SARAN}

Kesimpulan pada penelitian pengaruh Sikat Gigi Setiap Hari ( 21 hari) Dengan Pasta Gigi

Yang Mengandung Fluor menggunakan Tehnik Roll Terhadap Plak Skore di SDN Keramat 3 Desa Sungai Tabuk Keramat

1. Plak skor sebelum intervensi plak skor terendah 0.66, plak skor tertinggi 4.16, plak skor rata-rata 2.86 .

2. Plak skor sesudah intervensi plak skor terendah 0.00 , plak skor tertinggi 2.16, plak skor rata-rata 0.82

3. Ada pengaruh Sikat Gigi Setiap Hari ( 21 hari) Dengan Pasta Gigi Yang Mengandung Fluor menggunakan Tehnik Roll Terhadap Plak Skore di SDN Keramat 3 Desa Sungai Tabuk Keramat

Saran dalam penelitian ini : 
1. Diharapkan kepada guru dan orangtua murid untuk terus mengingatkan kepada muridnya agar menjaga kebersihan gigi dan mulutnya dengan menyikat gigi 2 kali sehari, pagi setelah sarapan dan malam sebelum tidur

2. Diharapkan kepada responden untuk mempertahankan kebersihan gigi dan mulutnya dengan selalu membiasakan menyikat gigi 2 kali sehari , pagi setelah sarapan dan malam sebelum tidur.

\section{DAFTAR PUSTAKA}

1. Houwink,B., dkk., 1993.Ilmu Kedokteran Gigi Pencegahan.Gadjah Mada University Press.Yogyakarta

2. Jamilah, M.,2010. Perbandingan Efektifitas Pasta Gigi Yang Mengandung Ekstrak Daun Sirih \& Fluor Terhadap Pertumbuhan Streptococus Mutans. usu. Medan

3. Kemenkes RI.,2012. Buku Panduan Pelatihan Kader Keehatan Gigi Dan Mulut Di Masyarakat. Jakarta. p:1

4. Machfoedz,I. dan Zein A.Y.,2005.Menjaga Kesehatan Gigi dan Mulut Anak - Anak Ibu Hamil. Penerbit Fitramaya. Surabaya

5. Mahendra,B.,2005.13 Jenis Tanaman Obat Ampuh.Penebar Swadaya.Jakarta

6. Mutmainah,M.,2013.Pengaruh Penggunaan Pasta Gigi Yang Mengandung Daun Sirih Terhadap Pebentukan Plak Dan Gingivitis Marginalis Kronis. Universitas Hassanudin Fakultas Kedokteran Gigi. Makasar

7. Notoatmodjo,S.,2002.Metodologi Pnelitian Kesehatan (edisi revisi).Rhmeka Cipta.Jakarta

8. Putri,M,H., Herjulianti,E., Nurjanah,N., 2010.Ilmu Pencegahan Penyakit Jaringan Keras dan Jaringan Pendukung Gigi Kedokteran.EGC.Jakarta

9. Rahmadhan,AG.,2010.Serba Serbi Kesehatan Gigi dan Mulut.Bukune.Jakarta

10. Riskesdes,2007. Badan Penelitian dan Pengembangan Kesehatan Kementrian RI. Jakarta

11. Sabir,A.,2005. Aktivitas antibakteri flavonoid propolis trigona $\mathrm{sp}$ terhadapbakteri streptococcusmutans(invitro,).(http://journal .unair.ac.id/filerPDF/DENTJ-38)

12. Sindoro,I.,Diktat.,1996. Perlindungan Khusus Departemen Kesehatan RI SPRG Surabaya

13. Sriyono, N,W.,2009, Pengantar IImu Kedokteran Gigi Pencegah. Medika. Fakultas UGM

14. Prasada D.B.G.D.I. 2016. Gambaran Perilaku Menggosok Gigi Pada Siswa Kelas Satu Dengan Karies Gigi di Wilayah Kerja Puskesmas Rendang Karangasem Bali (Indonesia digital Jurnal.php/article/View File)

15 Darwita R.R. dkk. 2011. Efektivitas Program Sikat Gigi Bersama Terhadap Risiko Karies Gigi pada Murid Sekolah Dasar (Indonesia digital Jurnal.php/article/View File)

16. Maruanaya M.A. dkk. 2015. Gambaran Status Gingiva Menurut Kebiasaan Menyikat Gigi Sebelum Tidur Malam Hari Pada siswa Sekolah Dasar Negeri 70 Manado (Indonesia digital Jurnal.php/article/View File)

17. Ristika R, 2014. Perbedaan Efektivitas Menyikat Gigi Antara Metode Bass dan Roll Terhadap Plak Gigi Di SDIT Muhammadiyah (Indonesia digital Jurnal.php/article/View File)

18. Widya,RR.,2011, Pengaruh Penggunaan Pasta Gigi Yang Mengandung Buah Strawberry Terhadap Pembentukan Plak. Fakultas Kedokteran Universitas Diponogoro. 